\title{
Patricio Ibarra y Germán Morong (eds.), Relecturas de la Guerra del Pacífico, avances y perspectivas. Santiago, UBO Ediciones, 2018, 300 págs.
}

Relecturas es corolario de una serie de investigaciones realizadas por un grupo de historiadores peruanos y chilenos entre 2016 y 2018 , y resultado de un acuerdo de cooperación entre la Universidad Bernardo O’Higgins y su Centro de Estudios Históricos. En conjunto, buscan romper con el paradigma de la publicación historiográfica tradicional con respecto a la Guerra del Pacífico y realizar, de esta manera, una obra colectiva, efectuando una relectura del conflicto armado que involucró a Chile, Perú y Bolivia y sus fenómenos asociados desde distintos puntos de vista y categorías analíticas.

El libro nace como una imperiosa necesidad de rehacer los conocimientos referentes a este hecho tan importante en la historia de los países involucrados, cuyos ecos son palpables hasta el día de hoy. El objetivo de la obra es principalmente aportar en la reinterpretación y debate del periodo, integrando una visión binacional de especialistas, como anteriormente se mencionó; peruanos y chilenos que revisaron antecedentes de prensa, de la administración de justicia, de la literatura, del clero, de los veteranos de guerra y de la historiografía tradicional, para redescubrir y reinterpretar el conflicto de 1879.

La obra fue producto del tercer Ciclo de Conferencias en Historia titulado "Relecturas de la Guerra del Pací- fico (1879-1884): avances y perspectivas", realizado en Santiago de Chile y en dependencias de la Universidad Bernardo O’Higgins, en Octubre de 2016.

Los capítulos que dan vida a esta obra siguen los lineamientos teóricos y empíricos de la historiografía tradicional y son la consignación de un rejuvenecimiento temático y teórico que busca reconstruir una serie de dinámicas y procesos que colindan estratégicamente con aspectos tradicionales ya explorados sobre la guerra y sus cursos más comunes.

Contextualizando, en 1879 estalló el conflicto estableciéndose como el enfrentamiento armado externo más importante en la historia de las naciones involucradas y en el que Chile se impuso a la alianza formada por Perú y Bolivia, reclamando así los ricos territorios salitreros de Antofagasta y Tarapacá. Al finalizar la pugna, en 1884, se produce una nueva modificación fronteriza y Chile reclama los territorios de Arica y Parinacota, regiones que marcarán la relación a futuro de los Estados. El conflicto, antecedentes, causas, desarrollo y consecuencias se han estudiado prácticamente desde el inicio del enfrentamiento. Hombres contemporáneos se hicieron cargo de la narración, desde su propio punto de vista, de los hechos en los que fueron partícipes, conocedores de primera fuente o testigos presenciales de los acon- 
tecimientos, volviéndose incluso cronistas de una historia trabajada en tiempo presente. Diego Barros Arana, Benjamín Vicuña Mackenna, Tomás Caivano, Mariano Paz Soldán, fueron parte de la estirpe de historiadores que analizaron y estudiaron este fenómeno reciente para ellos, entendiéndolo como algo trascendente para el futuro de cada nación que tomó parte en él.

Los combatientes, rememorando su experiencia bélica, contribuyeron escribiendo sobre sus propias historias de guerra o sobre las campañas en las que participaron, específicamente. De estos combatientes se deben realizar menciones aparte a veteranos chilenos como Francisco Machuca, Nicanor Molinare y Arturo Benavides Santos.

La obra inicia con el trabajo de David Home, titulado "La guerra contra España como antecedente de la Guerra del Pacífico:Opinión pública, prensay sociedad civil” donde el autor, mediante un proceso comparativo, identifica una trayectoria común entre ambos conflictos. Para dicho paralelismo, David Home analiza la prensa y la sociedad civil -soportes de la opinión pública-, señalando las peculiaridades y pormenores de cada suceso. En un principio, el autor analiza la prensa denominada "americanista", que alentaba la unión entre los países americanos y buscaba la incorporación de Chile al conflicto peruano-español de 1866. En la segunda parte del texto, el autor da a conocer el papel de la prensa durante la Guerra del Pacífico, destacando los servicios que estos medios realizaron durante las hostilidades, resaltando los esfuerzos que estos medios informativos realizaron para dirigir la opinión de la población civil a favor de los esfuerzos de guerra y divulgando discursos e íconos referentes al americanismo que debía ser defendido. Por último, el autor realiza una reflexión con respecto a las diferentes perspectivas que consideran a la Guerra contra España como referente de la Guerra del Pacífico, relacionando ambos conflictos desde un punto de vista de la cobertura informativa y comunicacional, revelando un discurso general de autoconsciencia nacional.

La segunda contribución, titulada “ ¡Los Hijos del Bío Bío en pie de guerra!: Iglesia, prensa y compromiso ciudadano durante la Guerra del Pacífico (1879-1881)", continúa con la temática anterior y corresponde al estudio del profesor Mauricio Rubilar. En él se nos permite examinar dos hechos trascendentes; el primero, la repercusión regional del conflicto en la sociedad de la zona del Bío-Bío y, el segundo, correspondiente al rol de la prensa en la movilización ciudadana y la obligación patriótica adquirida por los pobladores de la provincia. En su estudio, el autor analiza el papel que desempeñaron distintos actores sociales tales como la Iglesia Católica, la prensa local y las acciones que ambos estamentos sociales llevaron a cabo, para posibilitar una movilización ciudadana. Asimismo, da a conocer los inconvenientes que tuvieron para intensificar el patriotismo en los habitantes de la región antes mencionada. El análisis de la prensa regional, efectuado por el autor, muestra las diferentes aristas políticas y doctrinarias que caracterizaron el desarrollo de la sociedad chilena, constituyendo así una excelente fuente de entendimiento de los rasgos que distinguían a las principales ciudades de la otrora provincia de Concepción. Hablamos de Chillán, Arauco y del propio Gran Concepción. Así fue que 
instituciones como la Iglesia Católica y la prensa regional trataron de cohesionar y homogeneizar a la opinión pública en el esfuerzo de guerra, fomentando y legitimando comportamientos sociales, tanto a la élite regional, como a los grupos de estratos más populares, creando lugares comunes frente a la amenaza eventual de la mentada guerra.

José Chaupis, académico de la Universidad Nacional Mayor de San Marcos (Perú) nos presenta, en el tercer capítulo de la obra, su estudio titulado "La vida cotidiana a través de la justicia: los pleitos por injurias durante la ocupación chilena de Lima”. Desde una perspectiva jurídico institucional, evidencia la falta de historiografía relacionada a la ocupación de Lima por parte de las tropas chilenas desde enero de 1881 hasta octubre de 1883, en torno a la administración de justicia para la población limeña, sometida al dominio y sujeción militar chilena. Para el autor, la entrada de los soldados chilenos en la capital peruana no solo conllevó a la instauración de un imperio político-militar y económico de la ciudad, sino que además implementó un sistema que podríamos llamar jurídico-social. En este nuevo sistema instaurado por Chile se fijaron un conjunto de normas alternas a la jurisprudencia peruana. Dentro de este marco, la convivencia fue unos de los problemas más importantes de tuvo que soslayar la autoridad chilena, esto expresado en los conflictos cotidianos llevados a los tribunales de justicia. Chile instaura los juzgados de letras y del crimen en la capital limeña, los que son aceptados rápidamente por la sociedad peruana y extranjera, ya que se necesitaba una pronta solución a las disputas. Esta contribución está dividida en dos partes; la primera trata del proyecto político de jus- ticia criminal chileno en el Perú, que fue internalizado rápidamente por la población limeña. La segunda parte corresponde al estudio del impacto de estas nuevas normativas jurídicas y cómo fueron interpretadas por los diferentes actores sociales. Todo ello realizado a través del análisis de expedientes judiciales por injurias.

El cuarto capítulo corresponde al estudio de Gerardo Trillo, historiador y Director General del Centro de Servicios Bibliotecarios Especializados de la Biblioteca Nacional del Perú. Se titula "La Resistencia de la prensa. Panorama de la prensa regional peruana en la Guerra del Pacifico". En este capítulo, el autor realiza un detallado y metódico análisis de la prensa peruana regional, mostrándonos un panorama general en los años de la ocupación chilena del Perú, distinguiéndose en el estudio tres etapas en las que la prensa va variando en su temática y temperamento. En una primera fase, que acontece en 1879, la prensa se muestra con un aire de confianza en la victoria, llegando a constatarse un espíritu patriotero de los editores. La segunda fase observada se desarrolla durante 1880 , momento en que la prensa se muestra con una actitud de desasosiego y protesta, producido por las acciones del ejército chileno, buscando abiertamente la colaboración internacional y suplicando poner freno al proceder nefasto de las autoridades peruanas. La última etapa se desarrolla en el momento del ingreso de las tropas chilenas a Lima y se anula la prensa local. Este periodo es llamado "la resistencia de la prensa" o "periodismo de resistencia". Este aporte permite realizar un paralelismo que nos deja observar un conjunto de prácticas y representaciones que los editores muestran con respecto al enemi- 
go, chileno o peruano.

Claudio Véliz, dedicado a la crítica literaria, nos muestra un nuevo punto de vista sobre el conflicto del Pacífico de 1879. En "Representaciones Literarias chilenas sobre la Guerra del Pacífico (1879-1884)", nos entrega una perspectiva de las publicaciones literarias durante la década de 1930, años en los cuales la Guerra del Pacífico era el principal objeto de narrativa. En este capítulo, Véliz analiza las obras de Daniel Riquelme (1855-1912), Ramón Pacheco (1845-1888) y Pedro Sienna (1893-1972), examinando parte de las obras más destacadas de estos autores en búsqueda de una construcción y representación específica sobre la Guerra del Pacífico, representación que, según el autor de este estudio, ayudó a forjar una idea de nación que fomentó un ideal de magnificencia y dignidad respecto de los soldados chilenos durante el conflicto entre 1879 y 1884, elementos que perduraron en el imaginario chileno durante años. En el estudio se especifica que la Guerra del Pacífico no fue solo un hecho en el que se delimitó el territorio entre las naciones involucradas y que costó una gran cantidad de vidas para lograr este cometido, sino que además fue donde se erigió la piedra angular de legitimización para las identidades nacionales de chilenos, peruanos y bolivianos, destacando las victorias de los primeros y disminuyendo, en las narrativas, a los derrotados. Estas publicaciones de los años 30, cimentaron una visión en que peruanos y bolivianos se encontraban en un estamento inferior y en donde se resaltaban sus carencias con epítetos vinculados a la barbarie, indianidad y negritud. Estos adjetivos buscaban legitimar la visión propia de fortalecimiento y superioridad de los chilenos buscando debilitar los atributos de los vecinos del norte. Estas publicaciones fueron construcciones que perjudicaron y que además buscaron crear un prejuicio con respecto a las naciones enemistadas, que persisten latentes hasta nuestros días.

El sexto capítulo nos regala el estudio de Claudio Tapia, investigador del Centro de Estudios Humanísticos de la Universidad Técnica Federico Santa María, titulado "La construcción de la política exterior chilena en el contexto de la guerra y postguerra del Pacífico". Desde el punto de vista de la investigación, Tapia afirma que los hechos de 1879 fueron claves en el perfeccionamiento de la política exterior chilena. Desde que comenzó el conflicto, Chile visualizó que se encontraba en desmedro- en lo que a cuestiones diplomáticas se refiere- debido a la falta de experiencia, de práctica y por no poseer el personal idóneo para hacer valer sus pretensiones ante la comunidad internacional, debiendo soslayar, a pesar de estas condiciones, los apremios de los demás países latinoamericanos, de Estados Unidos y, posteriormente, para enfrentar las negociaciones de paz que pusieron término al conflicto. A pesar de la victoria chilena en la guerra, la paz en la región no fue alcanzada de manera inmediata. Esto, debido principalmente a las modificaciones territoriales que estos hechos conllevaron y a que Chile desde ese instante rompe el equilibrio regional, en lo que a poder militar se refiere, y pasa a ser una potencia regional. Este hecho, obviamente repercutió en las relaciones con las naciones vecinas y especialmente en la diplomacia estadounidense acostumbrada a mantener una hegemonía en el vecindario americano. Con la Guerra del Pacífico, Chile se vio obligado a establecer una diplomacia ac- 
tiva con países poco relevantes para lo que a su diplomacia se refiere.

La séptima parte de Relecturas se titula "El Presbítero Juan Vitaliano Berroa frente a la chilenización de Tacna y Arica (1904-1926): Un caso de resistencia civil", estudio a cargo de Ricardo Cubas, académico de la Universidad de los Andes. Cubas se hace cargo del proceso de chilenización desde el punto de vista del sacerdote peruano, oriundo de Tacna y Arica, en relación a las disposiciones administrativas aplicadas por los delegados de la ocupación, con respecto a la propiedad de la Iglesia, la identidad cultural y los derechos que poseía la Iglesia peruana en la zona. En el estudio, el autor analiza al Presbítero Berroa, actor principal en las dinámicas sociológicas locales orientadas a establecer una resistencia activa al gobierno chileno de Tacna y Arica en 1910, además de examinar el discurso antichileno del clérigo. Berroa consideraba como perjudiciales las medidas que imponían las autoridades chilenas en lo referido a prácticas religiosas y tradiciones populares milenarias en la región. El activismo del sacerdote se ve reflejado en tres ámbitos: primero, en lo intelectual, donde escribía ensayos publicados en medios de difusión en Tacna y Arica; el segundo ámbito corresponde al cívico-pastoral, donde Berroa utilizaba el púlpito y su cercanía con los fieles para promover una resistencia pacífica frente a las medidas políticas de chilenización dirigidas en contra de la Iglesia y la sociedad. Por último, en el ámbito legal, defendió los derechos civiles del clero peruano y realizó su propia defensa en contra de los cargos que las autoridades chilenas le imputaban. De esta manera, el estudio pone en el centro de la discusión historiográfica el rol de la Iglesia Católi- ca peruana en la defensa de tradiciones religiosas y populares propias del alma de la región, que no debían ser desterradas del seno de su gente por una administración afuerina.

El octavo capítulo se titula "Premios y recompensas para los veteranos de la Guerra del Pacífico", estudio realizado por Carlos Méndez. Este trabajo traza una cronología en la que se logra apreciar el afán del Estado chileno por otorgar premios, apoyar y recompensar de alguna manera a los hombres que valoró como héroes. Galardones que no solo se extendieron a la oficialidad, sino que también incluyó a los hombres pertenecientes a la tropa. Esta apreciación se logra vislumbrar en una trayectoria legal que institucionalizó la idea de resarcir a las viudas y familiares cercanos de los soldados caídos, además de integrar en estas medidas a los hombres que resultaron amputados durante los hechos de guerra. Para poner en marcha esta práctica, en 1881 el parlamento aprobó la "Ley de recompensas por la campaña contra Perú y Bolivia", compuesta por 35 artículos y estructurada de forma prolija. Las asistencias entregadas por esta Ley incluían becas de estudio para los hijos de padres fallecidos, entrega de prótesis para todos, soldados y civiles que resultaron con algún grado de invalidez y también establecía la conformación de comités de sanidad cuya misión fue la determinación del grado incapacidad física, estableciendo la categorización de "invalidez absoluta" o "invalidez relativa”, dependiendo de las cuales se asignaba la ayuda que el Estado entregaba.

Por último, esta obra culmina con el estudio de Patricio Ibarra, titulado “La victoria de la 'Nación en Ar- 
mas': Gonzalo Bulnes y la Guerra del Pacífico". En este último capítulo, Ibarra realiza un análisis de la obra, del nombrado anteriormente Gonzalo Bulnes "La Guerra del Pacífico", considerándola como una obra esencial para el discernimiento y contextualización del hecho de armas. Esto, dado la diversa información que contiene, la documentación utilizada, al detalle en el relato de los hechos y a la interpretación que Bulnes propone. Estos factores convierten a esta obra en la base de la historiografía chilena respecto de los hechos ocurridos en la guerra. Esto es evidente en tres consideraciones propuestas por el autor para ponderar el aporte de Bulnes. La primera consideración corresponde a los principios epistemológicos y a la escuela historiográfica a la que pertenece Bulnes. En segundo lugar, a la metodología que utiliza el autor, a las fuentes que recurre y su estilo narrativo. Por último, a la interpretación general que Bulnes hizo del conflicto en sus escritos. Así, Patricio Ibarra genera un análisis desde una perspectiva general de una de las obras más importantes para el estudio de la guerra que enfrentó a Chile contra el Perú y Bolivia, que permitió la reconstrucción de los hechos bélicos de la época y que ha sido utilizada como base principal para las investigaciones contemporáneas dedicadas al tema.

Relecturas no tiene otro objetivo más que convertirse en una contribución a la creación, discusión y renovación de la historiografía relacionada a la Guerra del Pacífico, proponiendo una mirada integradora de historiadores peruanos y chilenos desde el estudio de sus diferentes disciplinas e intereses de investigación. 